\title{
Revestimento cerâmico com granito e argila caulinítica
}

\section{(Ceramic tile with granite and kaolinitic clay)}

\author{
E. T. A. de Souza, S. N. Monteiro, C. M. F. Vieira \\ Laboratório de Materiais Avançados - LAMAV. \\ Universidade Estadual do Norte Fluminense - UENF \\ Av. Alberto Lamego, 2000, Campos dos Goytacazes, RJ, 28013-602 \\ vieira@uenf.br
}

\begin{abstract}
Resumo
Este trabalho teve por objetivo a obtenção de revestimento cerâmico prensado do tipo semiporoso por meio da mistura de argila plástica caulinítica e granito. Foram preparadas misturas com $0 \%, 20 \%, 30 \%$ e $40 \%$ em peso de granito. Para um estudo comparativo, avaliou-se também uma massa cerâmica industrial proveniente da região de Santa Gertrudes. Foram preparados corpos-de-prova por prensagem uniaxial para queima em temperaturas variando de 1000 a $1200{ }^{\circ} \mathrm{C}$. Nas amostras queimadas foram realizados ensaios tecnológicos para determinação da retração linear, resistência mecânica (flexão em 3 pontos) e absorção de água. Análise microestrutural foi realizada por microscopia eletrônica de varredura. Os resultados mostraram que a incorporação de granito à argila caulinítica não possibilitou uma redução da temperatura de queima necessária para se alcançar o patamar de $10 \%$ de absorção de água requerido por norma. Também foi observado um decréscimo da resistência mecânica com o aumento de granito incorporado. Em comparação com a massa industrial, tanto a argila caulinítica quanto as misturas elaboradas apresentaram uma composição química com menor teor de fundentes e maior perda ao fogo e comportamento refratário durante a queima.
\end{abstract}

Palavras-chave: argila, caulinita, granito, microestrutura, revestimento cerâmico.

\begin{abstract}
This work had for objective to obtain a pressed ceramic tile, of semiporous type, through mixtures of granite and kaolinitic plastic clay. Mixtures were prepared with addition of 0, 20, 30 e 40wt\% of granite to kaolinitic clay. For comparison, an industrial ceramic body from Santa Gertrudes, State of S. Paulo, was also evaluated. Specimens were prepared by uniaxial pressing followed by firing at temperatures varying from $1000^{\circ} \mathrm{C}$ to $1200^{\circ} \mathrm{C}$. The fired specimens were submitted to the following tests: linear shrinkage, mechanical strength (three point bending) and water absorption. Microstructural analysis was carried out by scanning electron microscopy. The results showed that the granite incorporation did not decrease the specified firing temperature to reach $10 \%$ of water absorption required by Brazilian standards. It was also observed that the mechanical strength was reduced with increasing granite incorporation. In comparison with the industrial body, both, the kaolinitic clay and the elaborated mixtures presented a chemical composition with lower flux content and higher loss on ignition as well as a refractory behavior during firing.
\end{abstract}

Keywords: clay, kaolinite, granite, microstructure, ceramic tile.

\section{INTRODUÇÃO}

Tradicionalmente no Brasil os revestimentos cerâmicos prensados, produzidos pela rota de preparação de massa a seco, são obtidos a partir de uma mistura de argilas fundentes conhecidas como taguá [1-3]. O pólo cerâmico de Santa Gertrudes, Estado de S. Paulo, é o grande produtor de revestimentos cerâmicos por esta rota, obtendo principalmente a tipologia referente ao grupo BIIb, semiporoso, de acordo com norma técnica NBR 13818 [4].

Estas argilas fundentes apresentam composições química e mineralógica bastante adequadas para as características de processamento atualmente empregadas pelas indústrias. A grande vantagem da rota de preparação de massa a seco em relação à via úmida é o menor custo de produção [5]. Para comercialização no mercado interno brasileiro, o fator custo é bastante relevante face ao baixo poder aquisitivo da maior parte do mercado consumidor.

O emprego de argilas cauliníticas como únicos componentes de massa para revestimento cerâmico não é adequado devido, sobretudo, ao seu comportamento refratário durante a queima o que dificulta a obtenção do nível de porosidade especificado por norma [6]. Em algumas regiões do país, os revestimentos cerâmicos por via seca são obtidos a partir de mistura de argilas plásticas de predominância caulinítica e argilas fundentes. As argilas cauliníticas, utilizadas em pequenas proporções $20-30 \%$ em massa, são extraídas de jazidas próximas às indústrias. Já as argilas fundentes são transportadas por longas distâncias o que acarreta aumento de custo. Além disso, para compensar a menor fundência da massa, é necessário um aumento da pressão de compactação e da temperatura de queima em 
comparação com os parâmetros tradicionalmente utilizados pelas indústrias da região de Santa Gertrudes. Em trabalho reportado na literatura [7] com amostras de $10 \times 20 \mathrm{~cm}^{2} \mathrm{de}$ misturas de argila plástica caulinítica de Campos dos Goytacazes e argila fundente queimadas em forno industrial foi concluído que, para a obtenção de revestimento cerâmico semiporoso, deve ser adicionada à argila caulinítica pelo menos $60 \%$ em massa de argila fundente. Misturas com percentuais menores de argila fundente apresentaram problemas de compactação.

O Estado do Rio de Janeiro é tradicionalmente um grande produtor de cerâmica vermelha [8]. Apesar de possuir um dos maiores mercados consumidor do país, não há produção de revestimentos cerâmicos. Há abundância de argilas plásticas cauliníticas, sobretudo nas regiões dos pólos de cerâmica vermelha. Entretanto, em relação às argilas fundentes, até o momento há apenas indícios de sua existência. Uma alternativa para substituição de argilas fundentes na composição de massa de revestimentos cerâmicos elaborados por via seca, pode ser a mistura entre argilas plásticas cauliníticas e fundente não plástico como granito, fonolito, feldspatóide, etc.

Neste sentido, o presente trabalho teve como objetivo verificar, em escala laboratorial, a possibilidade de obtenção de revestimento cerâmico semiporoso através da mistura de argila plástica caulinítica e granito.

\section{MATERIAIS E MÉTODOS}

\section{Materiais}

Para realização deste trabalho foram utilizados os seguintes materiais: argila plástica caulinítica, granito e massa industrial de revestimento cerâmico. A argila é empregada em composição de massa de cerâmica vermelha pelas indústrias do pólo cerâmico de Campos dos Goytacazes-RJ. A massa de revestimento cerâmico é composta por argilas fundentes

Tabela I - Composição química dos materiais (\% em peso). [Table I - Chemical composition of the materials (wt.\%).]

\begin{tabular}{cccc}
\hline Componentes & $\begin{array}{c}\text { Argila } \\
\text { caulinítica }\end{array}$ & $\begin{array}{c}\text { Massa } \\
\text { industrial }\end{array}$ & Granito \\
\hline $\mathrm{SiO}_{2}$ & 44,07 & 66,40 & 63,51 \\
\hline $\mathrm{Al}_{2} \mathrm{O}_{3}$ & 29,97 & 15,50 & 18,81 \\
\hline $\mathrm{Fe}_{2} \mathrm{O}_{3}$ & 9,15 & 5,92 & 4,44 \\
\hline $\mathrm{TiO}_{2}$ & 1,36 & 0,55 & 0,59 \\
\hline $\mathrm{CaO}$ & 0,22 & 0,35 & 3,48 \\
\hline $\mathrm{MgO}$ & 1,04 & 1,80 & 1,24 \\
\hline $\mathrm{Na}_{2} \mathrm{O}$ & 0,47 & 1,07 & 3,14 \\
\hline $\mathrm{K}_{2} \mathrm{O}$ & 1,44 & 3,48 & 3,78 \\
\hline $\mathrm{PF}$ & 12,03 & 4,50 & 0,59 \\
\hline
\end{tabular}

conhecidas como taguá e utilizadas por indústrias do pólo cerâmico de Santa Gertrudes-SP. O granito foi adquirido de uma mineradora de brita e pó de pedra da região de Campos. Na composição mineralógica deste granito há predomínio de plagioclásios (andesina e oligoclásio), quartzo e ortoclásio [9]. A Tabela I apresenta a composição química, obtida por fluorescência de raios X (Philips PW 2400), destes materiais.

Foram preparadas quatro misturas com incorporação de granito à argila caulinítica nas seguintes proporções: 10, 20, 30 e $40 \%$ em peso. As composições estudadas estão apresentadas na Tabela II. Nesta Tabela a sigla MI representa massa industrial enquanto $\mathbf{A}$, representa argila caulinítica e $\mathbf{G}$ granito.

Tabela II - Composições estudadas (\% em peso).

[Table II - Studied compositions (wt.\%).]

\begin{tabular}{lcccccc}
\hline Materiais & \multicolumn{6}{c}{ Composições } \\
& MI & A & A10G & A20G & A30G & A40G \\
\hline Massa & & & & & & \\
industrial & 100 & - & - & - & - & - \\
\hline Argila & & & & & & \\
caulinítica & - & 100 & 90 & 80 & 70 & 60 \\
\hline Granito & - & - & 10 & 20 & 30 & 40 \\
\hline
\end{tabular}

\section{Métodos}

Inicialmente foi realizada uma trituração a seco do granito em moinho de bolas até obter-se resíduo de $20 \%$ retido em malha ABNT 200 (abertura de $75 \mu \mathrm{m}$ ). A argila caulinítica foi triturada em almofariz de porcelana até total passagem em malha ABNT 40 (abertura de $425 \mu \mathrm{m}$ ). Em seguida, as composições elaboradas foram homogeneizadas a seco em moinho de bolas, com revestimento de porcelana, durante $60 \mathrm{~min}$.

Para realização dos ensaios tecnológicos foram preparados corpos-de-prova retangulares $\left(11,43 \times 2,54 \times 0,8 \mathrm{~cm}^{3}\right)$ por prensagem uniaxial a $25 \mathrm{MPa}$ e $8 \%$ de umidade. Em seguida, os corpos-de-prova foram secos em estufa a $110^{\circ} \mathrm{C}$ por $24 \mathrm{~h}$. A etapa de queima foi realizada em forno de laboratório nas temperaturas de 1000 a $1200{ }^{\circ} \mathrm{C}$, com intervalos de $50{ }^{\circ} \mathrm{C}$. A taxa de aquecimento empregada foi de $8{ }^{\circ} \mathrm{C} / \mathrm{min}$, com $6 \mathrm{~min}$ na temperatura de patamar. $\mathrm{O}$ resfriamento foi realizado desligando-se o forno. Após queima, as amostras foram submetidas aos seguintes ensaios tecnológicos: retração linear, absorção de água e tensão de ruptura à flexão ( 3 pontos).

A análise microestrutural foi realizada através da observação da superfície de fratura de misturas selecionadas em microscópio eletrônico de varredura ZEISS, modelo DSM 962.

\section{RESULTADOS E DISCUSSÃO}

A Tabela III apresenta a composição química das misturas elaboradas com granito e argila caulinítica. À medida que se aumenta o percentual de granito incorporado à argila, observa- 
se uma redução no teor de $\mathrm{Al}_{2} \mathrm{O}_{3}$ e na perda ao fogo, bem como aumento do teor dos fundentes alcalinos, $\mathrm{K}_{2} \mathrm{O}$ e $\mathrm{Na}_{2} \mathrm{O}$. Ocorre também um incremento no teor dos óxidos alcalinoterrosos, $\mathrm{CaO}$ e $\mathrm{MgO}$. Entretanto, a composição com o maior teor de granito incorporado à argila $\mathbf{A 4 0 G}$ apresenta diferenças significativas quando comparada com a massa industrial MI. $\mathrm{O}$ teor de $\mathrm{SiO}_{2}$ é ligeiramente menor e o teor $\mathrm{de}_{2} \mathrm{Ol}_{3}$ é muito elevado. A mistura A40G apresenta teores de óxidos alcalinoterrosos $(\mathrm{CaO}+\mathrm{MgO})$ pouco superiores à MI. Este resultado é devido ao elevado teor de $\mathrm{CaO}$ do granito proveniente dos feldspatos plagioclásios. $\mathrm{O}$ teor de óxidos alcalinos é inferior ao da massa MI. Já a perda ao fogo (PF) da mistura A40G com $7,45 \%$ é bem superior ao da massa MI com 4,5\%. Isto acarreta maior eliminação de gases e vapor d'água, exigindo uma queima mais cuidadosa. Além disso, a maior perda de massa durante a queima contribui para o incremento da retração.

Tabela III - Composição química das misturas elaboradas com argila caulinítica e granito (\% em peso).

[Table III - Chemical composition of the mixtures elaborated with kaolinitic clay and granite (wt.\%).]

\begin{tabular}{ccccc}
\hline Componentes & \multicolumn{4}{c}{ Misturas } \\
\hline & $\mathrm{A} 10 \mathrm{G}$ & $\mathrm{A} 20 \mathrm{G}$ & $\mathrm{A} 30 \mathrm{G}$ & $\mathrm{A} 40 \mathrm{G}$ \\
\hline $\mathrm{SiO}_{2}$ & 46,01 & 47,96 & 49,90 & 51,85 \\
\hline $\mathrm{Al}_{2} \mathrm{O}_{3}$ & 28,85 & 27,74 & 26,62 & 25,51 \\
\hline $\mathrm{Fe}_{2} \mathrm{O}_{3}$ & 8,68 & 8,21 & 7,74 & 7,27 \\
\hline $\mathrm{TiO}_{2}$ & 1,28 & 1,21 & 1,13 & 1,05 \\
\hline $\mathrm{CaO}$ & 0,55 & 0,87 & 1,20 & 1,52 \\
\hline $\mathrm{MgO}$ & 1,06 & 1,08 & 1,1 & 1,12 \\
\hline $\mathrm{Na}_{2} \mathrm{O}$ & 0,74 & 1,00 & 1,27 & 1,54 \\
\hline $\mathrm{K}_{2} \mathrm{O}$ & 1,67 & 1,91 & 2,14 & 2,38 \\
\hline $\mathrm{PF}$ & 10,89 & 9,74 & 8,60 & 7,45 \\
\hline
\end{tabular}

No diagrama de gresificação da Fig. 1, é mostrado o comportamento da absorção de água e da retração linear com o aumento da temperatura de queima para a argila caulinítica A e para a massa industrial de revestimento cerâmico MI. Pode-se observar que é nítida a diferença de comportamento da absorção de água entre a massa industrial e a argila caulinítica. A massa industrial apresenta um comportamento bastante fundente, com rápido decréscimo da porosidade a partir da temperatura inicial empregada $\left(1000^{\circ} \mathrm{C}\right)$. Já a $1050^{\circ} \mathrm{C}$ a MI apresenta total vitrificação com absorção de água praticamente nula. A $1200{ }^{\circ} \mathrm{C}$ foi observado um pequeno incremento da absorção de água devido provavelmente à eliminação de gás proveniente da redução de compostos de ferro [10]. Por outro lado, a argila caulinítica apresenta um comportamento refratário, com redução da porosidade (absorção de água) em função do aumento gradual da temperatura de queima. Este comportamento é devido ao elevado percentual de alumina e baixo percentual de óxidos fundentes.

Já a retração linear apresenta um comportamento similar para a argila caulinítica e massa industrial. Entretanto, a 1200 ${ }^{\circ} \mathrm{C}$ enquanto a argila caulinítica ainda apresenta retração, a massa industrial se expande.

A argila caulinítica só alcança o patamar máximo de absorção de água para revestimento semiporoso $(10 \%)$ a $1178{ }^{\circ} \mathrm{C}$. Nesta temperatura a retração linear obtida foi bastante elevada, 9,6\%. A comparação de parâmetros de processamento laboratoriais com industriais, como a temperatura de queima, deve ser vista com restrição. Nas condições laboratoriais utilizadas, a temperatura de $1178^{\circ} \mathrm{C}$ é significativamente superior à temperatura industrial utilizada no Brasil para obtenção de revestimento semiporoso, que é em torno de $1100^{\circ} \mathrm{C}$.

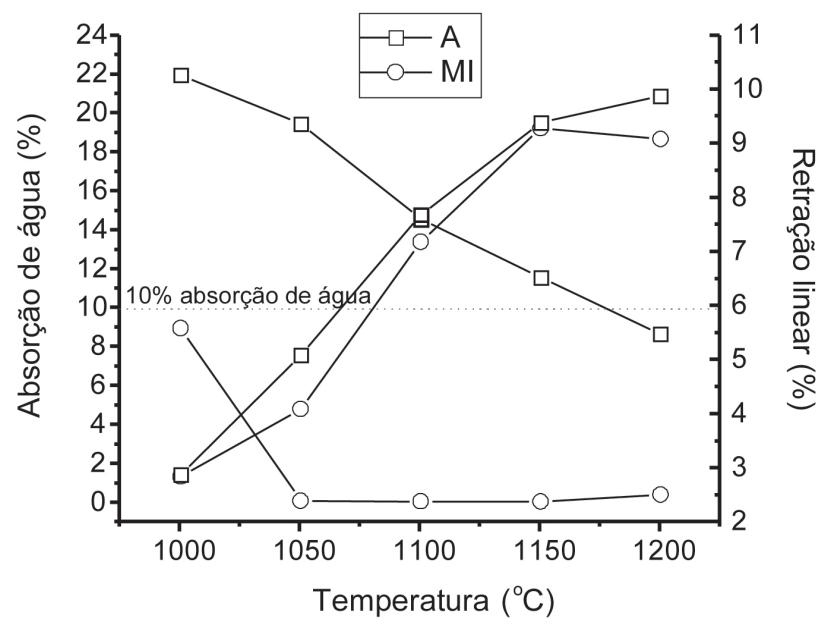

Figura 1: Diagrama de gresificação da argila caulinítica A e da massa industrial MI.

[Figure 1: Gresification diagram of the kaolinitic clay $\boldsymbol{A}$ and the industrial body MI.]

A Fig. 2 apresenta os diagramas de gresificação das misturas elaboradas com argila caulinítica e granito. Pode-se observar que o incremento da adição de granito à argila caulinítica não possibilitou uma redução da temperatura necessária para alcançar o valor de absorção de água de $10 \%$. Estas temperaturas variaram de $1163{ }^{\circ} \mathrm{C}$ para a mistura A20G a $1141{ }^{\circ} \mathrm{C}$ para a mistura $\mathbf{A 4 0 G}$.

Com relação à retração linear, observa-se que a incorporação de granito à argila caulinítica possibilitou uma significativa redução em comparação com os valores obtidos para a argila caulinítica. Este comportamento é devido à redução da perda de massa durante a queima e do aumento no teor de quartzo.

A Fig. 3 mostra o comportamento da tensão de ruptura à flexão das misturas elaboradas com o aumento da temperatura de queima. Observa-se que ocorre um incremento dos valores obtidos para todas as composições estudadas com o aumento da temperatura de queima. Este comportamento é devido à redução da porosidade e à maior consolidação microestrutural associada à sinterização que ocorre. A massa industrial MI apresenta valores de tensão de ruptura à flexão bem superior 

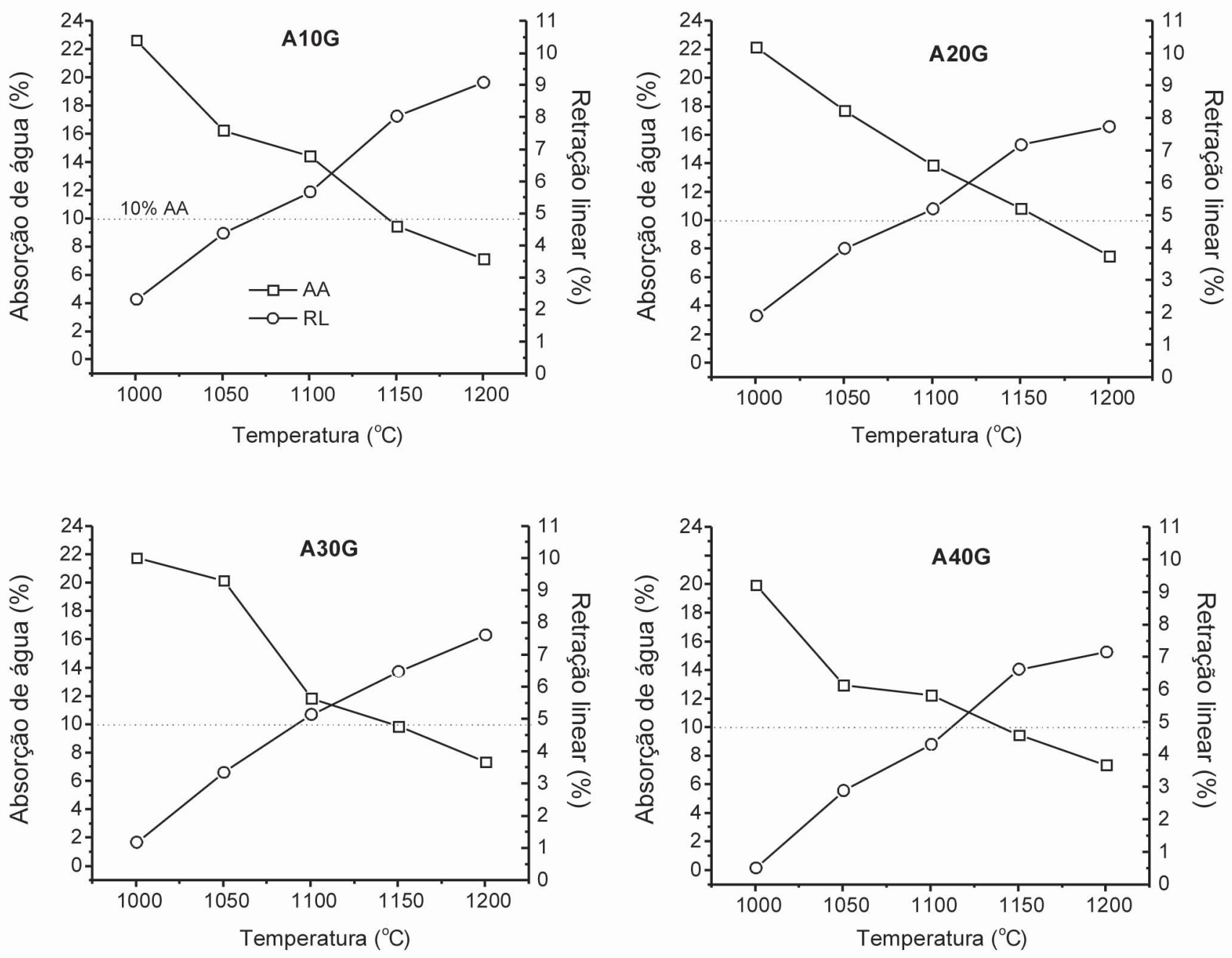

Figura 2: Diagrama de gresificação das misturas com argila caulinitica e granito.

[Figure 2: Gresification diagram of the mixtures with kaolinitic clay and granite.]

às demais composições, em virtude de sua maior fundência e conseqüentemente menor porosidade. Observa-se também que as composições elaboradas com granito apresentam valores de tensão de ruptura à flexão menor que a argila caulinítica pura. Isto é devido provavelmente ao incremento de quartzo que pode contribuir para o aparecimento de defeitos microestruturais devido à sua diferença de comportamento dilatométrico em comparação com os demais constituintes.

Valor de tensão de ruptura à flexão superior a $18 \mathrm{MPa}$ [4], mínimo recomendado para revestimento semiporoso, é alcançado pela massa industrial $\mathbf{M I}$ em todas as temperaturas avaliadas. Para a argila caulinítica sem incorporação de resíduo, este patamar é alcançado a $1210^{\circ} \mathrm{C}$. A mistura $\mathbf{A 4 0 G}$ não atingiu o mínimo necessário. Já as misturas A10G, A20G e A30G, alcançaram o patamar de $18 \mathrm{MPa}$ a 1145,1180 e $1175^{\circ} \mathrm{C}$, respectivamente.

As Figs. 4 a 6 exemplificam micrografias da superfícies de fratura da argila caulinítica, da mistura A40G e da massa industrial queimadas a $1100{ }^{\circ} \mathrm{C}$, respectivamente. Analisando as Figs. 4 e 5 verifica-se que tanto a argila caulinítica $\mathbf{A}$ quanto

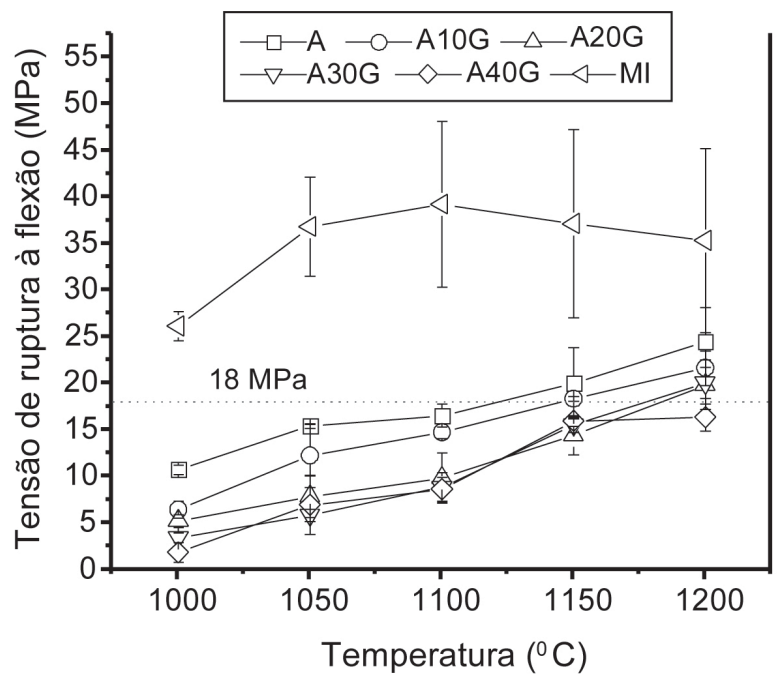

Figura 3: Tensão de ruptura à flexão das composições estudadas em função da temperatura de queima.

[Figure 3: Flexural rupture strength of the studied compositions as a function of the fired temperature.] 
a mistura com $40 \%$ de granito A40G apresentam uma superfície de fratura com textura rugosa, poros de grande tamanho e fissuras.

Na Fig. 6, que mostra a superfície de fratura da massa industrial MI, observa-se uma textura lisa, indicando um alto grau de vitrificação. Nota-se a presença de poros, de pequeno tamanho, e bolhas. $\mathrm{O}$ aparecimento de bolhas é, possivelmente, conseqüência do aprisionamento de gases provenientes da redução de compostos de ferro.

Tanto a argila caulinítica A quanto a mistura A40G, a textura rugosa e o nível de porosidade observado estão associados ao baixo poder de fundência e à elevada perda de massa durante a queima. Estes fatores dificultam o processo de vitrificação devido à baixa quantidade de fase líquida e formação de poros provenientes, sobretudo, da perda de água de constituição dos minerais argilosos.

A incorporação de granito à argila caulinítica não contribuiu para a redução na temperatura de queima necessária para se alcançar o valor máximo de absorção de água requerido por norma. O comportamento de queima das misturas elaboradas é ainda bastante refratário quando comparado com uma massa industrial. Como a granulometria do granito está relativamente fina, uma alternativa seria aumentar o seu teor incorporado à argila caulinítica. No entanto, isto pode comprometer a plasticidade da mistura e, conseqüentemente, ocasionar problemas de compactação levando à baixa resistência mecânica a seco das peças. A alternativa mais viável seria testar outros materiais com potencial fundente maior que o granito e buscar uma formulação com características mais próximas ao da massa industrial utilizada neste trabalho.

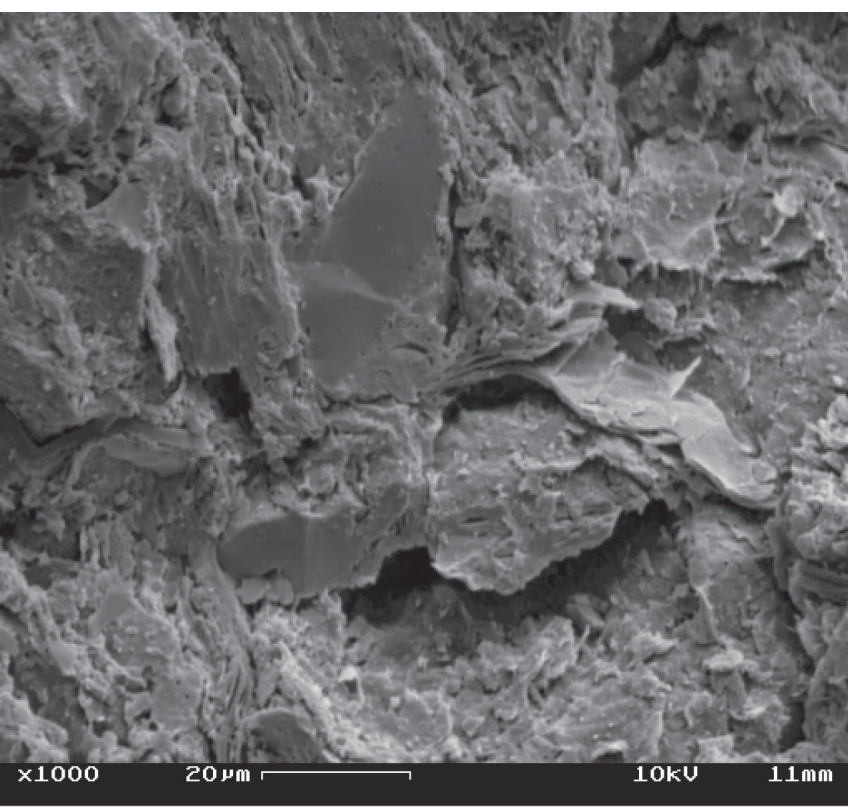

Figura 4: Micrografia obtida por MEV da superfície de fratura da argila caulinítica A queimada a $1100{ }^{\circ} \mathrm{C}$.

[Figure 4: SEM micrograph of the fracture surface of the kaolinitic clay $\boldsymbol{A}$ fired at $1100^{\circ} \mathrm{C}$.]

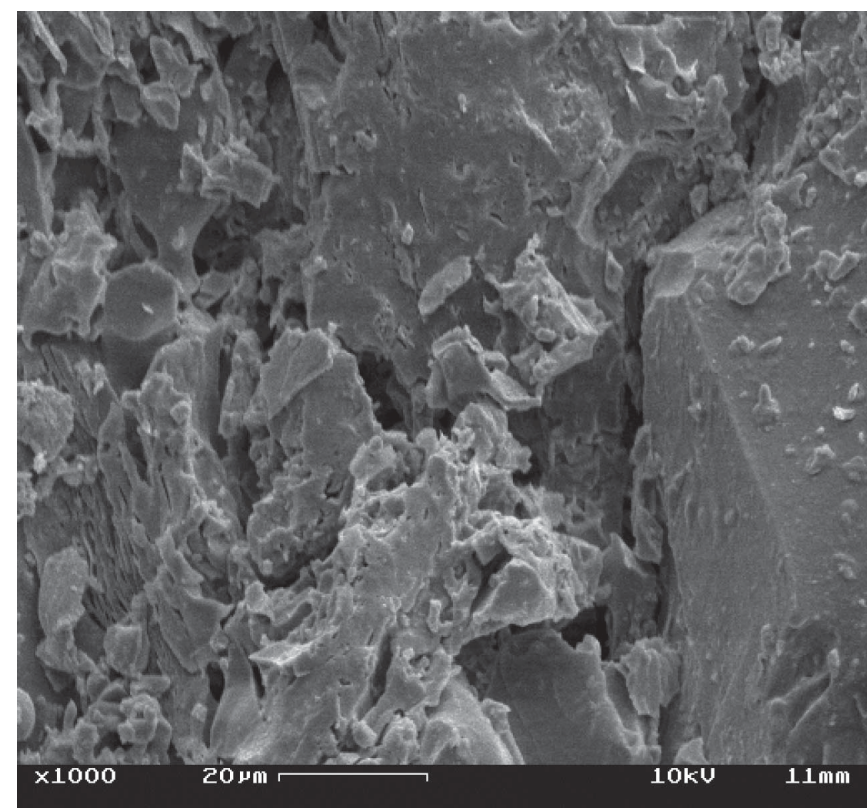

Figura 5: Micrografia obtida por MEV da superfície de fratura da mistura A40G queimada a $1100{ }^{\circ} \mathrm{C}$.

[Figure 5: SEM micrograph of the fracture surface of the mixture A40G fired at $1100^{\circ} \mathrm{C}$.]

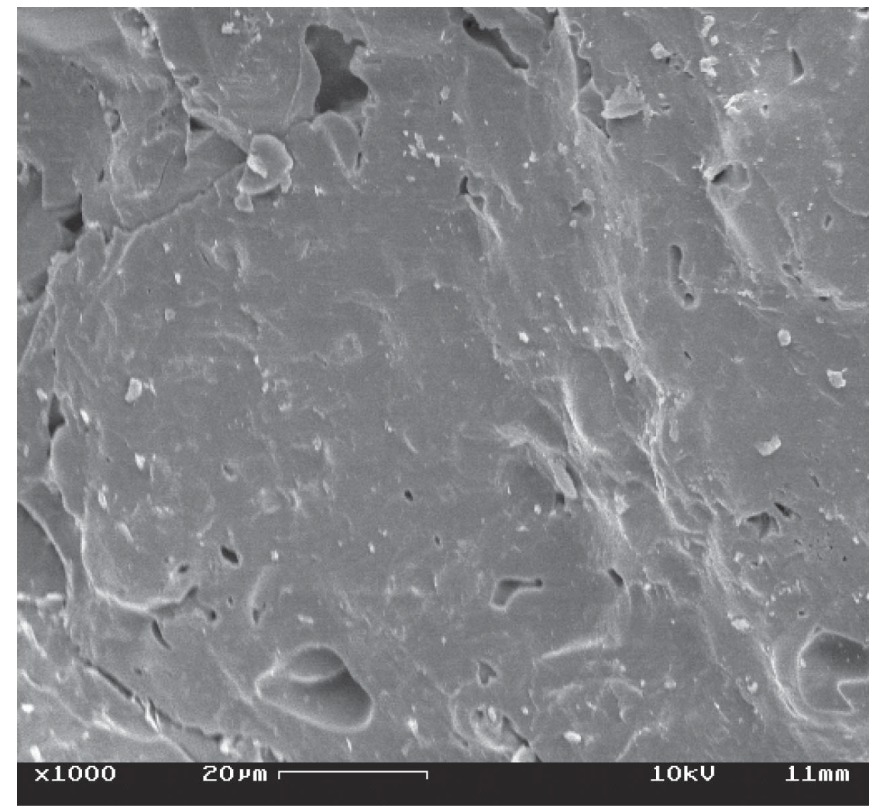

Figura 6: Micrografia obtida por MEV da superfície de fratura da massa industrial $\mathrm{MI}$ queimada a $1100{ }^{\circ} \mathrm{C}$.

[Figure 6: SEM micrograph of the fracture surface of the industrial body MI fired at $1100^{\circ} \mathrm{C}$.]

\section{CONCLUSÕES}

A argila caulinítica apresenta um comportamento refratário durante a queima. Os valores de absorção de água e tensão de ruptura à flexão, recomendados para revestimento semiporoso, somente foram alcançados na temperatura de $1175{ }^{\circ} \mathrm{C}$. Entretanto, a retração linear obtida foi elevada, 9,6\%.

A incorporação de granito à argila caulinítica contribuiu para 
reduzir o teor de alumina e aumentar o teor de fundentes. Entretanto, durante a queima não houve redução de temperatura para se alcançar o patamar desejado de $10 \%$ de absorção de água. Houve também uma redução da resistência mecânica, causada possivelmente pelo incremento de grãos de quartzo nas massas.

A melhor composição obtida visando à obtenção de revestimento semiporoso foi com $10 \%$ de incorporação de granito à argila caulinitica. Esta composição alcançou os valores de absorção de água e tensão de ruptura à flexão, recomendados para revestimento semiporoso, em temperatura $30{ }^{\circ} \mathrm{C}$ menor que a argila pura. Além disso, a retração linear também foi reduzida.

Por fim, observou-se que a incorporação de até $40 \%$ de granito à argila caulinítica estudada ainda apresenta diferenças significativas tanto na composição química quanto no comportamento de queima de uma típica massa industrial de revestimento cerâmico semiporoso.

\section{AGRADECIMENTOS}

Os autores agradecem à FAPERJ pelo apoio para realização deste trabalho, Processo no E-26151.544/2001.

\section{REFERÊNCIAS}

[1] J. F. M. Motta, A. Zanardo, M. C. Junior, Cerâmica Industrial 6, 2 (2001) 28.

[2] C. V. Santos, A. A. P. Chagas, J. Castral Jr., Anais do $43^{\circ}$ Congresso Brasileiro de Cerâmica, Florianópolis, SC (2001) p. 7701.

[3] L. A. Gaspar Jr., M. H. O. Souza, M. M. T. Moreno, Anais do $45^{\circ}$ Congresso Brasileiro de Cerâmica, Florianópolis, SC , (2001) p. 201801.

[4] NBR 13818 - Ensaios para quantificação das características físicoquímicas das Placas Cerâmicas. ABNT, Rio de Janeiro. (1997) 78 p. [5] L. Lolli, G. Nassetti, L. F. B. Marino, Cerâmica Industrial 5, 2 (2000) 23.

[6] J. E. E. Navarro, A. Albaro, Técnica Cerámica 91 (1981) 119.

[7] C. M. F. Vieira, S. N. Monteiro, J. Duailibi Filho, Cerâmica Industrial 6, 6 (2001) 43.

[8] SENAI - Serviço Nacional de Aprendizagem Industrial, Projeto Estratégico - SD 011-S - Estudo do Setor de Cerâmica Vermelha— Região Sudeste (1997).

[9] IPT - Instituto de Pesquisas Tecnológicas, Ensaios Tecnológicos em Amostra de Rocha, Certificado no 787100 (1991) p.8.

[10] A. E. Benlloch, J. L. A. Albaro, J. E. E. Navarro, Bol. Soc. Esp. Ceram. Vidr. 20, 1 (1986) 17.

(Rec. 03/09/03, Rev. 11/12/03, Ac. 02/04/04) 